\title{
Extensão Universitária como Prática Educativa na Promoção da Saúde
}

\begin{abstract}
Regis Rodrigues Santana'
Cristina Célia de Almeida Pereira Santana' Sebastião Benício da Costa Neto" Ênio Chaves de Oliveira'

'Universidade Federal de Goiás (UFG), Goiânia/GO - Brasil "Pontifícia Universidade Católica de Goiás (PUC-GO), Goiânia/GO - Brasil

RESUMO - Extensão Universitária como Prática Educativa na Promoção da Saúde ${ }^{1}$. O artigo objetivou averiguar as contribuições da extensão universitária na formação profissional e na promoção da saúde. Tratou-se de um estudo de revisão, com consulta às bases de dados LILACS, MEDLINE e Scielo em junho de 2019. Conforme critérios de elegibilidade, foram selecionados 18 artigos. Após síntese, os dados foram dispostos em tabelas e quadros. A abordagem metodológica mais utilizada foi a descritiva-qualitativa com enfoque no trabalho multidisciplinar, formação acadêmica e interação academia-comunidade. A extensão foi compreendida como estratégia para promover saúde e uma ferramenta factível para o desenvolvimento profissional. Considerou-se, todavia, necessário maior incentivo para seu fortalecimento e efetivação social.

Palavras-chave: Extensão Universitária. Educação em Saúde. Promoção da Saúde. Formação Profissional.
\end{abstract}

ABSTRACT - University Extension Program as an Educational Practice for Health Promotion. The aim of the article was to investigate the contributions of University Extension Programs in vocational training and health promotion. This was a review study, consulting the LILACS, MEDLINE and Scielo databases in June 2019. According to eligibility criteria, 18 articles were selected. After synthesis, the data were arranged in tables and charts. The descriptive-qualitative approach was the most used methodological approach with focus on multidisciplinary work, academic education and community-academy interaction. University extension was understood as a strategy to promote health and a feasible tool for professional development. However, it was considered necessary a greater incentive for its strengthening and social fulfillment.

Keywords: University Extension. Health Education. Health Promotion. Professional Qualification.

Educação \& Realidade, Porto Alegre, v. 46, n. 2, e98702, 2021. 1

http://dx.doi.org/10.1590/2175-623698702 
Extensão Universitária como Prática Educativa na Promoção da Saúde

\section{Introdução}

O Plano Nacional de Extensão Universitária, fomentado no início dos anos 2000, menciona que as atividades de extensão são realizadas por várias áreas de conhecimento, apresentando diferentes estratégias. Essas atividades constituem-se em um dos pilares da tríade ensino-pesquisa-extensão, favorecendo que discentes e docentes adquiram habilidades, competências e atitude crítica-reflexiva para atuarem junto à comunidade (Oliveira; Almeida Júnior, 2015; Alves et al., 2016).

$\mathrm{Na}$ área da saúde as estratégias aplicadas são diversificadas e objetivam estimular a aplicabilidade do conhecimento pelo aluno, bem como, constituir uma forma de comunicação junto à sociedade, especialmente para divulgar temas relacionados à promoção da saúde (Oliveira; Almeida Júnior, 2015; Deus; Krug, 2018).

Neste contexto, a ação de extensão universitária caracteriza-se como um processo educativo dinâmico que favorece a junção entre o ensino em sala de aula e o aprendizado, conforme proposto no planejamento pedagógico de curso, e no cotidiano social, por meio da vivência do cenário da realidade (Síveres, 2013; Minetto et al., 2016).

Para a comunidade, a ação de extensão oportuna um momento de participação ativa, discussão e reflexão em grupo para aquisição de conhecimentos sobre assuntos ligados ao processo saúde-doença e das boas práticas em saúde (Minetto et al., 2016; Silva et al., 2017).

Desta forma, a aproximação universidade-comunidade, com interlocução de saberes, estabelece contribuições para o aprofundamento da cidadania, fortalecimento da autonomia e a transformação social (Cortez; Silva, 2017; Silva et al., 2017).

Considerando os princípios do Sistema Único de Saúde (SUS), onde o modelo de atenção valoriza o princípio da integralidade, permeado pela prática humanizada e a promoção da saúde, bem como a necessidade de profissionais para atuar com competências específicas neste cenário, questiona-se: a implementação de ações de extensão universitária é um recurso favorável no processo de ensino-aprendizado para a atuação prática no âmbito da promoção da saúde?

Em vista disto, este artigo tem como objetivo realizar um levantamento das publicações nacionais que abordam as contribuições da ação de extensão universitária como estratégia para formação profissional e promoção da saúde.

\section{Métodos}

Para este estudo foi realizada uma revisão integrativa da literatura que incluiu a análise das publicações nacionais mais relevantes sobre as contribuições da ação de extensão universitária na promoção da saúde no Brasil, possibilitando reflexão e síntese do conhecimento sobre o tema, bem como proposição de sua aplicabilidade na prática em nosso contexto. 
Os artigos foram obtidos por meio de acesso ao Portal da Biblioteca Virtual em Saúde (BVS), com consulta às bases de dados LILACS (Literatura Latino Americana e do Caribe em Ciências da Saúde), MEDILINE (Medical Literature Analysis and Retrieval System Online) e SciELO (Scientific Electronic Library Online). Utilizou-se os Descritores: Extensão na relação comunidade-instituição, Promoção da Saúde, Educação em Saúde e Formação Profissional.

Como critérios para inclusão no estudo, determinou-se os artigos disponíveis na íntegra, publicados nos últimos cinco anos (2015-2019), nos idiomas inglês ou português, que abordassem a temática nos seguintes eixos: desenvolvimento de Projetos de Extensão Universitária para o ensino-aprendizado em saúde e ações de extensão promotoras da saúde na comunidade. Os critérios de exclusão foram os artigos que não apresentaram relação com as questões norteadoras do estudo, desenvolvidos com foco em outras áreas do ensino ou que abordavam outros níveis de atenção à saúde.

A busca pelos descritores possibilitou o levantamento inicial de 5.194 artigos, dos quais apenas 134 atenderam aos critérios de inclusão. Após a leitura dos resumos e realizando a exclusão de artigos duplicados, 48 foram selecionados para leitura na íntegra. Destes, apenas 18 artigos foram considerados para análise e discussão, por sua relação próxima às questões norteadoras do estudo, conforme demonstrado na Figura 1.

Figura 1 - Fluxograma Com a Descrição dos Artigos Selecionados, Excluídos e Incluídos na Busca para o Estudo

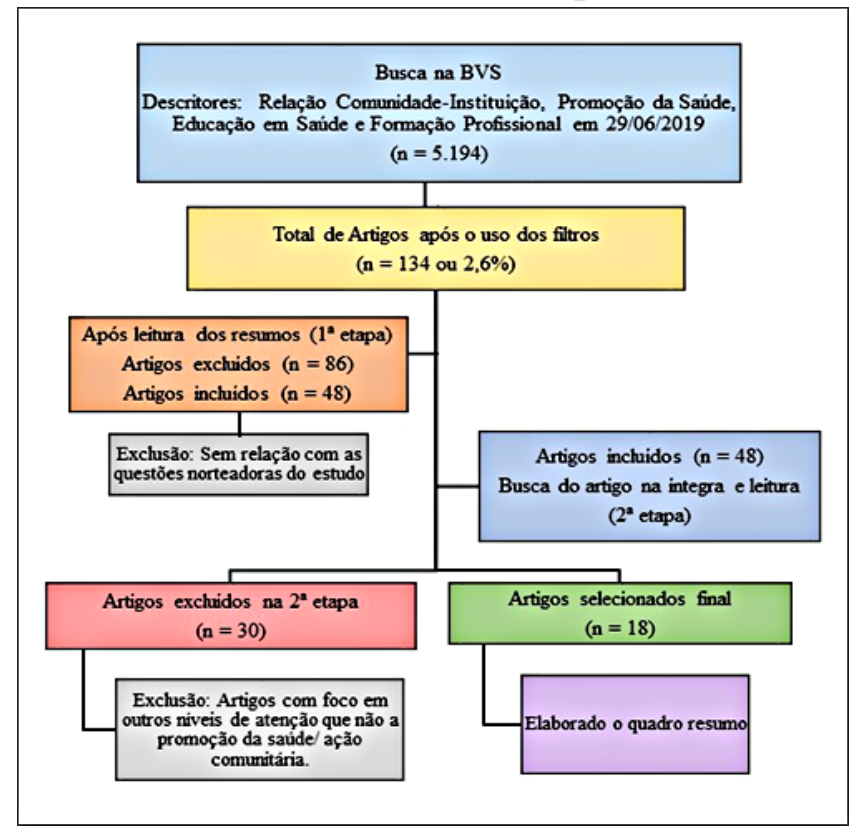

Fonte: Fluxograma delineado pelos autores (2019). 
Extensão Universitária como Prática Educativa na Promoção da Saúde

\section{Resultados}

Foram identificadas durante o levantamento inúmeras publicações voltadas para atividades de extensão universitária, porém, priorizou-se as que abordavam ações voltadas para a promoção da saúde, coordenadas e/ou executadas por profissionais ou discentes da área da saúde. Nos 18 artigos selecionados para este estudo, obteve-se a seguinte distribuição por ano de publicação: 2015 (quatro), 2016 (três), 2017 (cinco), 2018 (quatro) e 2019 (dois). Os dados foram organizados por ano de publicação e dispostos visando a sua descrição nos seguintes aspectos: título, autoria, objetivo, método, resultados e/ou conclusões (Quadro 1).

As produções estão concentradas em cinco áreas, com o maior número de artigos voltados a equipe multidisciplinar e de enfermagem. Dentre os métodos utilizados pelos autores destacam-se os trabalhos com abordagem qualitativa, os estudos documentais e os artigos de revisão. Apesar de o conteúdo geral estar centrado nas ações e experiências desenvolvidas pelas instituições de ensino superior para a promoção da saúde, o enfoque foi nas seguintes categorias: formação acadêmica, inter-relação academia e comunidade e aplicação de estratégias educativas/metodologias.

A maioria dos trabalhos foram publicados nas regiões Nordeste e Sudeste e estão direcionados para a esfera academia-comunidade, configurando a necessidade de investigar a vivência do discente na realidade local e o impacto das ações de extensão universitária em sua formação e no contexto social. Os dados de caracterização dos artigos estão demonstrados na Tabela 1.

Tabela 1 - Distribuição das Publicações Conforme Local, Área de Concentração do Estudo, Método e Foco Temático, 2019

\begin{tabular}{lcc}
\hline Região de publicação & $\mathbf{N}$ & $\mathbf{( \% )}$ \\
\hline Nordeste & 7 & 38,9 \\
Norte & 1 & 5,5 \\
Sudeste & 6 & 33,4 \\
Sul & 4 & 22,2 \\
Total & 18 & 100 \\
\hline Área de concentração & $\mathbf{N}$ & $\mathbf{( \% )}$ \\
\hline Multidisciplinar & 7 & 38,9 \\
Enfermagem & 6 & 33,4 \\
Odontologia & 3 & 16,7 \\
Medicina & 1 & 5,5 \\
Educação Física & 1 & 5,5 \\
Total & 18 & 100 \\
\hline
\end{tabular}


Santana; Santana; Costa Neto; Oliveira

\begin{tabular}{lcc}
\hline Método & $\mathbf{N}$ & $\mathbf{( \% )}$ \\
\hline Estudo Bibliográfico/documental & 3 & 16,6 \\
Descritivo/qualitative & 12 & 66,6 \\
Revisão Sistemática & 1 & 5,6 \\
Descritivo-transversal & 1 & 5,6 \\
Observacional-transversal/quantitative & 1 & 5,6 \\
Total & 18 & 100 \\
\hline Foco temático & $\mathbf{N}$ & $\mathbf{( \% )}$ \\
\hline Formação acadêmica & 9 & 50,0 \\
Inter-relação academia e comunidade & 8 & 44,5 \\
Estratégias educativas/ Aplicação de metodologias & 1 & 5,5 \\
Total & 18 & 100 \\
\hline
\end{tabular}

Fonte: Elaboração dos autores.

Quadro 1 - Síntese das características das publicações referentes às contribuições da ação de extensão universitária na promoção da saúde no Brasil (2019)

\begin{tabular}{|c|c|c|c|c|c|c|}
\hline No & ANO & TITULO & $\underset{\text { (ES) }}{\operatorname{AUTOR}}$ & OBJETIVO (S) & METODO & $\begin{array}{l}\text { RESULTADOS/ } \\
\text { CONCLUSÕES }\end{array}$ \\
\hline 01 & 2015 & $\begin{array}{l}\text { Extensão uni- } \\
\text { versitária na } \\
\text { promoção da } \\
\text { saúde infantil: } \\
\text { analisando } \\
\text { estratégias } \\
\text { educativas }\end{array}$ & $\begin{array}{l}\text { Costa et } \\
\text { al, } 2015 \text {. }\end{array}$ & \begin{tabular}{|l} 
Descrever e \\
analisar as \\
estratégias \\
educativas \\
desenvolvidas \\
para promover \\
saúde e preve- \\
nir doenças, \\
utilizadas em \\
um projeto de \\
extensão uni- \\
versitária
\end{tabular} & $\begin{array}{l}\text { Estudo } \\
\text { documen- } \\
\text { tal }\end{array}$ & $\begin{array}{l}\text { - O desenvolvimento de } \\
\text { estratégias educativas } \\
\text { mostrou a importância do } \\
\text { papel dos acadêmicos na } \\
\text { promoção da saúde; } \\
\text { - As intervenções educati- } \\
\text { vas mostraram-se eficazes } \\
\text { para a disseminação do } \\
\text { conhecimento ao público } \\
\text { infantil, bem como esclare- } \\
\text { cer dúvidas sobre os assun- } \\
\text { tos debatidos a partir das } \\
\text { experiências cotidianas } \\
\text { considerando o contexto } \\
\text { social. }\end{array}$ \\
\hline 02 & 2015 & $\begin{array}{l}\text { Extensão uni- } \\
\text { versitária na } \\
\text { ótica de acadê- } \\
\text { micos: o agente } \\
\text { fomentador } \\
\text { das Diretrizes } \\
\text { Curriculares } \\
\text { Nacionais }\end{array}$ & $\begin{array}{l}\text { Moimaz } \\
\text { et al, } \\
2015 .\end{array}$ & $\begin{array}{l}\text { Analisar a } \\
\text { percepção de } \\
\text { acadêmicos de } \\
\text { Odontologia } \\
\text { acerca de um } \\
\text { programa de } \\
\text { extensão, sob a } \\
\text { ótica da apro- } \\
\text { ximação com } \\
\text { as Diretrizes } \\
\text { Curriculares } \\
\text { Nacionais. }\end{array}$ & $\begin{array}{l}\text { Estudo } \\
\text { descriti- } \\
\text { vo- quali- } \\
\text { tativo }\end{array}$ & $\begin{array}{l}\text { - A extensão universitária } \\
\text { oportunizou a reflexão, } \\
\text { sentido e aplicabilidade } \\
\text { dos conteúdos teóricos } \\
\text { apreendidos, aprofundan- } \\
\text { do seu entendimento acer- } \\
\text { ca da saúde coletiva; } \\
\text { - Contribui para ampliação } \\
\text { de formas alternativas de } \\
\text { atuação e execução do tra- } \\
\text { balho, aprimoramento de } \\
\text { habilidades e atitudes; } \\
\text { - O programa possibilitou } \\
\text { um ambiente propício para } \\
\text { trabalhar cooperativamen- } \\
\text { te em equipe. }\end{array}$ \\
\hline
\end{tabular}


Extensão Universitária como Prática Educativa na Promoção da Saúde

\begin{tabular}{|c|c|c|c|c|c|c|}
\hline 03 & 2015 & $\begin{array}{l}\text { Motivações de } \\
\text { acadêmicos } \\
\text { de enferma- } \\
\text { gem atuantes } \\
\text { em projetos } \\
\text { de extensão } \\
\text { universitária: } \\
\text { a experiência } \\
\text { da faculdade } \\
\text { ciências da } \\
\text { saúde do Trai- } \\
\text { rí/UFRN. }\end{array}$ & $\begin{array}{l}\text { Oliveira; } \\
\text { Almeida } \\
\text { Júnior, } \\
2015 .\end{array}$ & $\begin{array}{l}\text { Compreender } \\
\text { os motivos que } \\
\text { levaram os } \\
\text { estudantes de } \\
\text { enfermagem } \\
\text { da Faculdade } \\
\text { de Ciências da } \\
\text { Saúde do Trairí } \\
\text { a participarem } \\
\text { dos projetos de } \\
\text { extensão uni- } \\
\text { versitária da } \\
\text { instituição. }\end{array}$ & $\begin{array}{l} \\
\text { Estudo } \\
\text { descriti- } \\
\text { vo-explo- } \\
\text { ratório } \\
\text { analítico } \\
\text { com abor- } \\
\text { dagem } \\
\text { qualita- } \\
\text { tiva }\end{array}$ & $\begin{array}{l}\text { - A extensão é ponte que } \\
\text { liga a universidade com } \\
\text { a sociedade e ferramenta } \\
\text { que possibilita trabalho } \\
\text { coletivo; } \\
\text { - Estabelece uma relação } \\
\text { entre as orientações cur- } \\
\text { riculares e possibilita a } \\
\text { formação do profissional } \\
\text { crítico-reflexivo; } \\
\text { - É interação entre univer- } \\
\text { sidade e sociedade e entre } \\
\text { teoria e a prática, permi- } \\
\text { tindo reflexão sobre o ato, } \\
\text { avaliando e aprendendo a } \\
\text { partir das experiências nos } \\
\text { espaços sociais do proces- } \\
\text { so saúde-doenças. } \\
\end{array}$ \\
\hline 04 & 2015 & $\begin{array}{l}\text { Educação } \\
\text { social e infân- } \\
\text { cia: atuação } \\
\text { e formação } \\
\text { profissional } \\
\text { no Projeto } \\
\text { Brincadeiras } \\
\text { com meninos } \\
\text { e meninas dele } \\
\text { na rua. }\end{array}$ & $\begin{array}{l}\text { Volpini et } \\
\text { al, } 2015 \text {. }\end{array}$ & $\begin{array}{l}\text { Apresentar } \\
\text { os princípios } \\
\text { do projeto e } \\
\text { analisar os } \\
\text { fundamentos } \\
\text { presentes na } \\
\text { formação e } \\
\text { atuação pro- } \\
\text { fissional de } \\
\text { educadores } \\
\text { sociais. } \\
\end{array}$ & $\begin{array}{l}\text { Pesquisa } \\
\text { qualita- } \\
\text { tiva }\end{array}$ & $\begin{array}{l}\text { - Os educadores possuem } \\
\text { visão positiva de suas expe- } \\
\text { riências noprojeto; } \\
\text { - A metodologia influência } \\
\text { na atuação profissional e } \\
\text { na forma que veem e inter- } \\
\text { ferem nas situações do seu } \\
\text { cotidiano. }\end{array}$ \\
\hline 05 & 2016 & $\begin{array}{l}\text { Cuidado à saú- } \\
\text { de da mulher } \\
\text { na extensão } \\
\text { universitária: } \\
\text { abordagem de } \\
\text { uma experi- } \\
\text { ência }\end{array}$ & $\begin{array}{l}\text { Calil, et } \\
\text { al, 2016. }\end{array}$ & \begin{tabular}{|l|} 
Descrever a \\
experiência \\
no desenvolvi- \\
mento de uma \\
atividade de \\
extensão inter- \\
disciplinar.
\end{tabular} & $\begin{array}{l}\text { Estudo } \\
\text { transver- } \\
\text { sal, des- } \\
\text { critivo }\end{array}$ & $\begin{array}{l}\text { - Cabe uma intensificação } \\
\text { das estratégias de promo- } \\
\text { ção da saúde sexual junto a } \\
\text { população estudada; } \\
\text { - Reforça o papel da edu- } \\
\text { cação para incentivar o } \\
\text { autocuidado com base em } \\
\text { projetos; } \\
\text { - Incentivou os primeiros } \\
\text { passos dos alunos de gra- } \\
\text { duação na compreensão do } \\
\text { cuidado à saúde da mulher, } \\
\text { coleta e análise citopato- } \\
\text { lógica; } \\
\text {-Para os bolsistas envolvi- } \\
\text { dos no projeto, significou } \\
\text { melhor qualificação do } \\
\text { aprendizado acadêmico. }\end{array}$ \\
\hline 06 & 2016 & $\begin{array}{l}\text { Promoção de } \\
\text { saúde bucal e } \\
\text { Síndrome de } \\
\text { Down: inclu- } \\
\text { são e quali- } \\
\text { dade de vida } \\
\text { por meio da } \\
\text { extensão uni- } \\
\text { versitária }\end{array}$ & $\begin{array}{l}\text { Ferreira } \\
\text { et al, } \\
2016 .\end{array}$ & $\begin{array}{l}\text { Identificar as } \\
\text { percepções } \\
\text { de pais e/ou } \\
\text { responsáveis } \\
\text { sobre a saúde } \\
\text { bucal; } \\
\text { Formular um } \\
\text { manual sobre } \\
\text { escovação } \\
\text { dentária e en- } \\
\text { contrar recur- } \\
\text { sos lúdicos de } \\
\text { manejo com- } \\
\text { portamental } \\
\text { para o paciente } \\
\text { com Síndrome } \\
\text { de Down. }\end{array}$ & $\begin{array}{l}\text { Pesquisa } \\
\text { qualita- } \\
\text { tiva }\end{array}$ & $\begin{array}{l}\text { - Facilitou a aproximação } \\
\text { dos pacientes com os pro- } \\
\text { fissionais; } \\
\text { - Observou-se melhora do } \\
\text { conhecimento e da cons- } \\
\text { cientização sobre a impor- } \\
\text { tância da saúde bucal na } \\
\text { Síndrome de Down; } \\
\text { - Os pais/responsáveis e } \\
\text { profissionais podem esten- } \\
\text { der e adaptar os conheci- } \\
\text { mentos obtidos para outras } \\
\text { deficiências; } \\
\text { - Percebida como funda- } \\
\text { mental na formação dos } \\
\text { alunos mostrando a im- } \\
\text { portância/necessidade de } \\
\text { atividades de promoção e } \\
\text { prevenção em saúde bucal } \\
\text { nessa população. }\end{array}$ \\
\hline
\end{tabular}


Santana; Santana; Costa Neto; Oliveira

\begin{tabular}{|c|c|c|c|c|c|c|}
\hline 07 & 2016 & $\begin{array}{l}\text { Percepção de } \\
\text { acadêmicos de } \\
\text { enfermagem } \\
\text { sobre o cuida- } \\
\text { do em saúde } \\
\text { mental em } \\
\text { domicílio: uma } \\
\text { abordagem } \\
\text { qualitativa } \\
\end{array}$ & $\begin{array}{l}\text { Lima et } \\
\text { al, } 2016 .\end{array}$ & $\begin{array}{l}\text { Compreender } \\
\text { a percepção de } \\
\text { acadêmicos de } \\
\text { enfermagem } \\
\text { sobre o cuida- } \\
\text { do em saúde } \\
\text { mental em } \\
\text { domicílio. }\end{array}$ & $\begin{array}{l}\text { Pesquisa } \\
\text { descritiva } \\
\text { explora- } \\
\text { tória com } \\
\text { aborda- } \\
\text { gem qua- } \\
\text { litativa }\end{array}$ & $\begin{array}{l}\text { - A Extensão Universitária } \\
\text { em Saúde Mental foi per- } \\
\text { cebida como oportunidade } \\
\text { para o crescimento pessoal } \\
\text { e acadêmico; } \\
\text { - Propicia reformulação de } \\
\text { conceitos; } \\
\text { - É facilitadora para o cui- } \\
\text { dado humanizado. } \\
\end{array}$ \\
\hline 08 & 2016 & $\begin{array}{l}\text { Impacto de } \\
\text { uma expe- } \\
\text { riência ex- } \\
\text { tensionista } \\
\text { na formação } \\
\text { universitária }\end{array}$ & $\begin{array}{l}\text { Moraes et } \\
\text { al, } 2016 .\end{array}$ & $\begin{array}{l}\text { Analisar o im- } \\
\text { pacto do proje- } \\
\text { to de extensã̃o } \\
\text { universitária } \\
\text { na formação de } \\
\text { estudantes do } \\
\text { curso de Odon- } \\
\text { tologia. }\end{array}$ & $\begin{array}{l}\text { Estudo } \\
\text { descritivo }\end{array}$ & $\begin{array}{l}\text { - A extensão é a oportu- } \\
\text { nidade de envolvimento } \\
\text { mais profundo entre uni- } \\
\text { versidade e sociedade, fator } \\
\text { diferencial na formação do } \\
\text { profissional; } \\
\text {-O lado "humanista" é } \\
\text { trabalhado intensamente } \\
\text { nesse tipo de atividade, } \\
\text { somando conhecimento } \\
\text { técnico e experiência pes- } \\
\text { soal para o futuro profis- } \\
\text { sional. }\end{array}$ \\
\hline 09 & 2017 & $\begin{array}{l}\text { A importância } \\
\text { da extensão } \\
\text { universitária } \\
\text { na graduação } \\
\text { e prática pro- } \\
\text { fissional de } \\
\text { enfermeiros }\end{array}$ & $\begin{array}{l}\text { Oliveira } \\
\text { et al., } \\
2017 \text {. }\end{array}$ & $\begin{array}{l}\text { Conhecer o } \\
\text { significado das } \\
\text { experiências } \\
\text { extensionistas } \\
\text { vividas na } \\
\text { graduação e } \\
\text { sua aplicação } \\
\text { na vida pro- } \\
\text { fissional para } \\
\text { enfermeiros }\end{array}$ & $\begin{array}{l}\text { Pesquisa } \\
\text { com abor- } \\
\text { dagem } \\
\text { qualita- } \\
\text { tiva }\end{array}$ & $\begin{array}{l}\text {-A extensão é ambiente } \\
\text { fecundo para aprender a } \\
\text { valorizar diferentes saberes } \\
\text { construídos cotidianamen- } \\
\text { te por contextos e atores } \\
\text { sociais diversos; } \\
\text { - O processo ensino- } \\
\text { aprendizagem se desloca } \\
\text { da mera transmissão de } \\
\text { conhecimento para a ri- } \\
\text { queza das relações sociais, } \\
\text { para a problematização e } \\
\text { transformação da realida- } \\
\text { de, integrando docentes e } \\
\text { demais trabalhadores. } \\
\end{array}$ \\
\hline 10 & 2017 & $\begin{array}{l}\text { Pesquisa-ação: } \\
\text { promovendo } \\
\text { educação em } \\
\text { saúde com } \\
\text { adolescentes } \\
\text { sobre infecção } \\
\text { sexualmente } \\
\text { transmissível }\end{array}$ & $\begin{array}{l}\text { Cortez; } \\
\text { Silva, } \\
\text { 2017. }\end{array}$ & \begin{tabular}{l|} 
Identificar \\
as dúvidas \\
dos alunos de \\
uma escola \\
pública federal \\
sobre Infecção \\
Sexualmente \\
Transmissível \\
e propor uma \\
abordagem ou \\
metodologia \\
educacional.
\end{tabular} & \begin{tabular}{|l|} 
Estudo \\
descriti- \\
vo- qua- \\
litativo \\
(Pesquisa- \\
ação)
\end{tabular} & $\begin{array}{l}\text { - A parceria escola e saúde } \\
\text { é uma das alternativas de } \\
\text { promover a saúde para os } \\
\text { adolescentes, por meio da } \\
\text { interação dos profissionais } \\
\text { de educação e saúde; } \\
\text { - A integração de outros } \\
\text { setores foi conveniente } \\
\text { para o estabelecimento } \\
\text { da educação em saúde do } \\
\text { adolescente; } \\
\text { - Respeitar e compartilhar } \\
\text { os saberes dos discentes, } \\
\text { utilizando elementos que } \\
\text { os mesmos ou o grupo pro- } \\
\text { põem, favorecendo a ação } \\
\text { de educação em saúde. } \\
\end{array}$ \\
\hline 11 & 2017 & $\begin{array}{l}\text { A extensão } \\
\text { universitária } \\
\text { como meio de } \\
\text { transformac̃ão } \\
\text { social e profis- } \\
\text { sional }\end{array}$ & $\begin{array}{l}\text { Des- } \\
\text { landes; } \\
\text { Arantes, } \\
2017 .\end{array}$ & $\begin{array}{l}\text { Discutir as } \\
\text { possibilidades } \\
\text { da extensão } \\
\text { universitária } \\
\text { como possível } \\
\text { mecanismo de } \\
\text { transformação } \\
\text { dos diversos } \\
\text { sujeitos envol- } \\
\text { vidos. }\end{array}$ & $\begin{array}{l}\text { Pesquisa } \\
\text { bibli- } \\
\text { ográfica e } \\
\text { documen- } \\
\text { tal }\end{array}$ & $\begin{array}{l}\text {-Deve-se divulgar os } \\
\text { projetos de extensão } \\
\text { existentes e incentivar o } \\
\text { desenvolvimento de novos } \\
\text { projetos entre os alunos, } \\
\text { cientificando-os da impor- } \\
\text { tância da participação, o } \\
\text { valor agregado ao currículo } \\
\text { acadêmico e a preparação } \\
\text { para a vida profissional; } \\
\text {-A extensão universitária é } \\
\text { considerada um dos pila- } \\
\text { res do ensino superior no } \\
\text { Brasil, o que fomenta não } \\
\text { somente a formação profis- } \\
\text { sional e humanística, mas } \\
\text { também a transformação } \\
\text { social. }\end{array}$ \\
\hline
\end{tabular}

Educação \& Realidade, Porto Alegre, v. 46, n. 2, e98702, 2021. 
Extensão Universitária como Prática Educativa na Promoção da Saúde

\begin{tabular}{|c|c|c|c|c|c|c|}
\hline 12 & 2017 & $\begin{array}{l}\text { Competências } \\
\text { para promoção } \\
\text { da saúde em } \\
\text { formandos dos } \\
\text { cursos da área } \\
\text { da saúde }\end{array}$ & $\begin{array}{l}\text { Carvalho } \\
\text { et al, } \\
2017 .\end{array}$ & $\begin{array}{l}\text { Avaliar o grau } \\
\text { de competên- } \\
\text { cias de promo- } \\
\text { ção da saúde } \\
\text { dentre os } \\
\text { formandos dos } \\
\text { cursos da área } \\
\text { da saúde. }\end{array}$ & $\begin{array}{l}\text { Estudo } \\
\text { obser- } \\
\text { vacional } \\
\text { trans- } \\
\text { versal e } \\
\text { quantita- } \\
\text { tivo }\end{array}$ & $\begin{array}{l}\text { - Estudos abordam o im- } \\
\text { pacto positivo do uso de } \\
\text { jogos lúdicos e pedagógicos } \\
\text { para a educação em saúde } \\
\text { com adolescentes; } \\
\text { - Aponta a necessidade de } \\
\text { capacitação e aprimora- } \\
\text { mento de técnicas para } \\
\text { melhorar a inter-relação } \\
\text { entre as diferentes equipes, } \\
\text { para construir o conheci- } \\
\text { mento e desenvolver ações } \\
\text { de promoção da saúde com } \\
\text { resultados positivos; } \\
\text { - Recomenda pesquisas } \\
\text { mais aprofundadas sobre } \\
\text { competências na área da } \\
\text { saúde. }\end{array}$ \\
\hline 13 & 2017 & $\begin{array}{l}\text { Inter-relação } \\
\text { das ações de } \\
\text { educação em } \\
\text { saúde no con- } \\
\text { texto da Estra- } \\
\text { tégia } \\
\text { Saúde da } \\
\text { Família: per- } \\
\text { cepções do } \\
\text { enfermeiro }\end{array}$ & $\begin{array}{l}\text { Vieira et } \\
\text { al, } 2017 .\end{array}$ & $\begin{array}{l}\text { Conhecer as } \\
\text { percepções } \\
\text { do enfermei- } \\
\text { ro acerca da } \\
\text { inter-relação } \\
\text { das ações de } \\
\text { educação em } \\
\text { saúde no con- } \\
\text { texto da estra- } \\
\text { tégia saúde da } \\
\text { família. }\end{array}$ & $\begin{array}{l}\text { Estudo } \\
\text { descriti- } \\
\text { vo-explo- } \\
\text { ratório } \\
\text { qualita- } \\
\text { tivo }\end{array}$ & $\begin{array}{l}\text {-A ação educativa é ativida- } \\
\text { de inerente ao trabalho do } \\
\text { enfermeiro; } \\
\text {-Ẽ necessário expandir as } \\
\text { práticas educacionais para } \\
\text { fortalecer a participaccão } \\
\text { social e a autonomia do } \\
\text { usuário; } \\
\text { - É preciso avaliar a edu- } \\
\text { cação em saúde tomando } \\
\text { como princípios os pre- } \\
\text { ceitos do SUS, pois é uma } \\
\text { prática que sustenta a } \\
\text { promocão da saúde; } \\
\text { - O profissional necessita } \\
\text { conhecer as vulnerabili- } \\
\text { dades da prática educativa } \\
\text { buscando alternativas para } \\
\text { superá-las. }\end{array}$ \\
\hline 14 & 2018 & $\begin{array}{l}\text { A percepção } \\
\text { de pais sobre } \\
\text { projeto de } \\
\text { extensão uni- } \\
\text { versitária em } \\
\text { escola amazô- } \\
\text { nica }\end{array}$ & $\begin{array}{l}\text { Souza; } \\
\text { Carva- } \\
\text { lho, } 2018 .\end{array}$ & $\begin{array}{l}\text { Identificar as } \\
\text { percepções } \\
\text { de pais sobre } \\
\text { as atividades } \\
\text { do projeto } \\
\text { de extensão } \\
\text { realizada pelo } \\
\text { profissional de } \\
\text { saúde no âmbi- } \\
\text { to escolar. }\end{array}$ & $\begin{array}{l}\text { Estudo } \\
\text { descritivo } \\
\text { qualita- } \\
\text { tivo }\end{array}$ & $\begin{array}{l}\text {-Percebeu-se que os pais } \\
\text { são sensíveis e compre- } \\
\text { endem a importância de } \\
\text { atividades de extensão no } \\
\text { âmbito da escola; } \\
\text { - O projeto de extensão no } \\
\text { ambiente escolar é uma } \\
\text { prática eficaz para ensinar } \\
\text { e divulgar boas práticas } \\
\text { para promoção da saúde } \\
\text { para os escolares, família e } \\
\text { comunidade. }\end{array}$ \\
\hline 15 & 2018 & $\begin{array}{l}\text { A Extensão } \\
\text { Universitária } \\
\text { e a Promoção } \\
\text { da Saúde no } \\
\text { Brasil: Revisão } \\
\text { Sistemática }\end{array}$ & $\begin{array}{l}\text { Sampaio } \\
\text { et al, } \\
2018 .\end{array}$ & $\begin{array}{l}\text { Descrever e } \\
\text { refletir sobre } \\
\text { a contribuição } \\
\text { da extensão } \\
\text { universitária } \\
\text { para a imple- } \\
\text { mentação e } \\
\text { desenvolvi- } \\
\text { mento de ações } \\
\text { de promoção } \\
\text { em saúde no } \\
\text { Brasil }\end{array}$ & $\begin{array}{l}\text { Revisão } \\
\text { sistemáti- } \\
\text { ca de } \\
\text { literatura }\end{array}$ & $\begin{array}{l}\text { - Mostraram-se relevantes } \\
\text { a criação e ampliação das } \\
\text { redes de interação e de } \\
\text { apoio junto aos usuários, } \\
\text { profissionais de serviços } \\
\text { sociais e de saúde, bem } \\
\text { como o fortalecimento da } \\
\text { gestão participativa e do } \\
\text { controle social; } \\
\text { - A extensão é percebida } \\
\text { como favorecedora para a } \\
\text { conscientização sobre as } \\
\text { determinaçôes do processo } \\
\text { saúde-doença e o cuidado } \\
\text { de si. }\end{array}$ \\
\hline
\end{tabular}




\begin{tabular}{|c|c|c|c|c|c|c|}
\hline 16 & 2018 & $\begin{array}{l}\text { Extensão } \\
\text { universitária } \\
\text { em saúde } \\
\text { ginecológica } \\
\text { de mulheres } \\
\text { trabalhadoras: } \\
\text { educação para } \\
\text { promoção da } \\
\text { saúde }\end{array}$ & $\begin{array}{l}\text { Barros; } \\
\text { Franco, } \\
2018 .\end{array}$ & \begin{tabular}{|l|} 
Desvelar a \\
percepção \\
de mulheres \\
trabalhado- \\
ras sobre a \\
consulta de \\
enfermagem \\
em ginecologia \\
no contexto da \\
saúde ocupa- \\
cional; \\
Compreender \\
os benefícios \\
de um projeto \\
de extensão \\
universitária, \\
voltado à saúde \\
ginecológica \\
de mulheres \\
trabalhadoras. \\
\end{tabular} & \begin{tabular}{|l|} 
Estudo ex- \\
ploratório \\
descritivo \\
de abor- \\
dagem \\
qualita- \\
tiva
\end{tabular} & $\begin{array}{l}\text { - Promoveu vínculo profis- } \\
\text { sional-cliente; } \\
\text { - A aprendizagem é ativa e } \\
\text { significativa, por meio da } \\
\text { autonomia conferida ao } \\
\text { extensionista; } \\
\text { - A integração ensino, ser- } \\
\text { viço e comunidade é apre- } \\
\text { endida como um grande } \\
\text { benefício para a população } \\
\text { atendida; } \\
\text { - É implementação de } \\
\text { novas formas de educação } \\
\text { em saúde }\end{array}$ \\
\hline 17 & 2019 & $\begin{array}{l}\text { Para além } \\
\text { da formação } \\
\text { tradicional em } \\
\text { saúde: Experi- } \\
\text { ência de Edu- } \\
\text { cação Popular } \\
\text { em Saúde } \\
\text { na formação } \\
\text { médica }\end{array}$ & $\begin{array}{l}\text { Rios; } \\
\text { Caputo, } \\
2019 .\end{array}$ & $\begin{array}{l}\text { Apresentar e } \\
\text { analisar os im- } \\
\text { pactos de uma } \\
\text { ação extensio- } \\
\text { nista baseada } \\
\text { na Educação } \\
\text { Popular em } \\
\text { Saúde }\end{array}$ & $\begin{array}{l}\text { Estudo } \\
\text { qualita- } \\
\text { tivo }\end{array}$ & $\begin{array}{l}\text { - O ensino tradicional da } \\
\text { medicina, por vezes, ne- } \\
\text { gligência o ser humano em } \\
\text { toda a sua potencialidade, } \\
\text { bem como seus contextos } \\
\text { sociais, políticos e cultu- } \\
\text { rais; } \\
\text { - Poucas são as possibilida- } \\
\text { des nos currículos de atua- } \\
\text { ção real em comunidade; } \\
\text { - As atividades práticas se } \\
\text { restringem muitas vezes ao } \\
\text { âmbito hospitalar; } \\
\text { - Escassas são as oportuni- } \\
\text { dades de trocas e diálogos } \\
\text { com discentes de outros } \\
\text { cursos de graduação; } \\
\text { - A extensão universitária } \\
\text { pode favorecer importan- } \\
\text { tes processos de mudança } \\
\text { no ensino médico ao pos- } \\
\text { sibilitar uma compreensão } \\
\text { ampla dos indivíduos, de } \\
\text { suas relações e de seus mo- } \\
\text { dos de viver no mundo. } \\
\end{array}$ \\
\hline 18 & 2019 & $\begin{array}{l}\text { A importância } \\
\text { da extensão } \\
\text { nas universida- } \\
\text { des brasileiras } \\
\text { e a transição } \\
\text { do reconhe- } \\
\text { cimento ao } \\
\text { descaso }\end{array}$ & $\begin{array}{l}\text { Koglin; } \\
\text { Koglin, } \\
2019 .\end{array}$ & $\begin{array}{l}\text { Realizar uma } \\
\text { reflexão te- } \\
\text { órica sobre a } \\
\text { importância da } \\
\text { Extensão Uni- } \\
\text { versitária nas } \\
\text { universidades } \\
\text { brasileiras, } \\
\text { seu processo } \\
\text { de reconheci- } \\
\text { mento a partir } \\
\text { de políticas } \\
\text { como o Progra- } \\
\text { ma Nacional } \\
\text { de Extensão } \\
\text { Universitária } \\
\text { - PROEXT e o } \\
\text { descaso diante } \\
\text { das políticas } \\
\text { de austeridade } \\
\text { nos dias atuais. }\end{array}$ & \begin{tabular}{|l|} 
Pesquisa \\
documen- \\
tal
\end{tabular} & $\begin{array}{l}\text {-As universidades desen- } \\
\text { volvem ações de extensão } \\
\text { em diversas áreas como } \\
\text { saúde, educação, meio } \\
\text { ambiente, cultura, esporte, } \\
\text { entre outras, apresentando } \\
\text { algumas delas abrangência } \\
\text { regional; } \\
\text {-Tem grande impacto nas } \\
\text { regiões em que se insere; } \\
\text { - No atual panorama as Po- } \\
\text { líticas econômicas e sociais } \\
\text { sofrem reformas e cortes } \\
\text { orçamentários que podem } \\
\text { impactar negativamente o } \\
\text { desenvolvimento das ações } \\
\text { de extensão universitária; } \\
\text {-Diante dos contextos } \\
\text { econômico, político e so- } \\
\text { cial vivenciados no Brasil, } \\
\text { essa união de forças torna- } \\
\text { se ainda mais relevante e } \\
\text { urgente. }\end{array}$ \\
\hline
\end{tabular}

Fonte: Elaboração dos autores. 
Extensão Universitária como Prática Educativa na Promoção da Saúde

\section{Discussão}

Os dados obtidos permitiram identificar três categorias que serão descritas a seguir: A extensão universitária como estratégia pedagógica e prática educativa junto à comunidade, A extensão universitária como um recurso dinâmico para a formação profissional e a promoção da saúde e Os desafios para implementação das ações de extensão no âmbito da saúde.

\section{A Extensão Universitária como Estratégia Pedagógica e Prática Educativa Junto à Comunidade}

Pontua-se que a análise da evolução do ensino superior revela um processo dinâmico que está correlacionado às transformações ocorridas em vários contextos como o político, econômico e social (Vieira et al., 2017; Sampaio et al., 2018; Koglin; Koglin, 2019; Rios; Caputo, 2019).

Desta forma, a sociedade impulsiona a aproximação das instituições com o cenário social e o desenvolvimento de estratégias para formação de profissionais mais preparados para a execução de suas competências, e a geração e difusão de conhecimentos para a comunidade (Oliveira; Almeida Júnior, 2015; Moraes et al., 2016; Oliveira et al., 2017; Deslandes; Arantes, 2017; Barros; Franco, 2018).

Uma destas estratégias, pactuada por leis como o Plano Nacional de Educação, é a extensão universitária. Percebida como um movimento interdisciplinar, de cunho educativo-científico e inerente a cada projeto de curso, visa favorecer a interação entre o docente-discente e a comunidade, e facultar o compromisso das universidades de contribuir para a transformação social (Deslandes; Arantes, 2017; Barros; Franco, 2018; Koglin; Koglin, 2019; Rios; Caputo, 2019).

Enfatiza-se que como processo educativo, a extensão universitária proporciona o intercâmbio entre o saber e o fazer, por meio da aplicação prática dos conhecimentos adquiridos no ambiente da sala de aula, articulando o processo de ensino por meio da ação em cenários reais (Costa et al., 2015; Oliveira; Almeida Júnior, 2015; Moimaz et al., 2015; Calil et al., 2016; Ferreira et al., 2016; Cortez; Silva, 2017; Rios; Caputo, 2019).

É ressaltado que a interação entre a academia e a sociedade, por meio da extensão, é amplamente discutida e utilizada para a formação dos profissionais da saúde. Sua implementação está respaldada, e impulsionada, pelos princípios do sistema de saúde vigente no Brasil, o SUS (Lima et al., 2016; Calil et al., 2016; Vieira et al., 2017; Koglin; Koglin, 2019; Rios; Caputo, 2019).

Em decorrência da necessidade de formação de profissionais para atuarem no âmbito da saúde, dentro do conceito proposto pelo SUS, foram elaboradas as Diretrizes Curriculares Nacionais (DCN). Elas possuem conceitos abrangentes e contemplam, entre outros, a formação profissional voltada para o trabalho, a diversificação de cenários 
de prática e a integração ensino-serviço-gestão-comunidade. As DCN representam um marco por determinar um modelo para orientação pedagógico-curricular e fomentar a criação de inúmeros programas voltados para capacitação de profissionais objetivando consolidar o SUS como modelo de qualidade na atenção à saúde (Moimaz et al., 2015; Carvalho et al., 2017; Rios; Caputo, 2019).

Destaca-se, nos requisitos para formação do profissional de saúde o desenvolvimento de competências específicas que irão possibilitar a execução de ações em todos os níveis de atenção, junto ao indivíduo ou coletividade, com qualidade e ética, discernimento crítico-reflexivo e corresponsabilização social (Oliveira; Almeida Júnior, 2015; Moimaz et al., 2015; Carvalho et al., 2017; Barros; Franco, 2018; Rios; Caputo, 2019).

A vivência de extensão universitária oportuniza experiências aos discentes, direcionando-os para atitudes responsáveis e seguras, o que contribui para a promoção da comunicação entre a universidade e o ambiente externo e interliga desta forma o ensino, a pesquisa e a extensão (Sampaio et al., 2018).

Neste panorama, a extensão universitária é concebida pelos autores como uma estratégia fundamental e peculiar, com caráter educativo, científico-cultural e tecnológico, que favorece o desenvolvimento das competências dos profissionais da saúde delineadas no projeto pedagógico-curricular (Moimaz et al., 2015; Calil et al., 2016; Deslandes; Arantes, 2017; Rios; Caputo, 2019). Percebe-se que a integração docentediscente-comunidade em contextos reais e cotidianos, com suas particularidades e vulnerabilidades, oportuniza aos alunos uma dinâmica que aprimora o saber-fazer, permitindo a junção entre o conhecimento aprendido teoricamente e o conhecimento oriundo da própria experiência (Oliveira; Almeida Júnior, 2015; Volpini et al., 2015; Ferreira et al., 2016; Moraes et al., 2016; Oliveira et al., 2017; Vieira et al., 2017).

O desenvolvimento das competências, nas ações de extensão, amplia-se pela vivência, pela resolução de problemas, pela reflexão críticaconstrutiva, pela autonomia, pelo trabalho em equipe e pela participação ativa dos indivíduos nos processos de produção de saúde (Lima et al., 2016; Cortez; Silva, 2017; Sampaio et al., 2018; Barros; Franco, 2018; Rios; Caputo, 2019).

Concebe-se, ao analisar esta categoria, que as ações de extensão universitária propiciam a integração entre o ensino, a pesquisa e a extensão, pois promovem a associação entre universidade e a sociedade, além de prestar serviços assistenciais e favorecer, sobretudo, o desenvolvimento de competências e o conhecimento.

\section{A Extensão Universitária Como um Recurso Dinâmico Para a Formação Profissional e a Promoção da Saúde}

Nas ações voltadas para promoção da saúde, a atividade extensionista destaca-se pela característica integradora. O conhecimento levado à comunidade também é permeado pelos saberes locais ou populares. A permuta de conhecimentos exprime um forte componente 
Extensão Universitária como Prática Educativa na Promoção da Saúde

para propiciar a reformulação de conceitos, aprendizagem significativa sobre o processo saúde-doença e aumento da adesão às boas práticas em saúde (Costa et al., 2015; Calil et al., 2016; Ferreira et al., 2016; Lima et al., 2016; Cortez; Silva, 2017; Oliveira et al., 2017; Sampaio et al., 2018; Souza; Carvalho, 2018).

Salienta-se que durante a graduação é exercitada a tríade ensinopesquisa e extensão. $\mathrm{O}$ aluno por meio da ação extensionista, direcionado e estimulado pelo docente, tem a oportunidade de demonstrar e aprimorar seu conhecimento, elaborar planejamentos e aplicar metodologias ativas para abordagem mais assertiva junto à comunidade. Desta forma, o desenvolvimento da estratégia permite o aprimoramento de competências, habilidades e atitudes, além das assimiladas na academia (Costa et al., 2015; Moimaz et al., 2015; Calil et al., 2016; Moraes et al., 2016; Oliveira et al., 2017; Deslandes; Arantes; 2017; Rios, Caputo; 2019).

Um aspecto considerado relevante na prática da ação comunitária é a oportunidade de perceber o outro, suas concepções e perspectivas. Na proposta da integralidade da assistência, o principal desafio do profissional é a capacidade de identificar e delimitar as reais necessidades de saúde e de cuidado. A percepção do outro e a escuta qualificada são fundamentais para o planejamento de ações efetivas que garantam qualidade, humanização na assistência e valorização dos sujeitos (Moimaz et al., 2015; Calil et al., 2016; Lima et al., 2016; Moraes et al., 2016; Cortez; Silva, 2017; Souza; Carvalho, 2018; Barros; Franco, 2018; Rios; Caputo, 2019).

As avaliações realizadas, após a aplicação das ações de extensão, sugeriram que os acadêmicos foram estimulados a valorizar os processos educativos e preventivos, bem como ampliar a percepção do trabalho em equipe e de sua importância no contexto da promoção da saúde (Costa et al., 2015; Volpini et al., 2015; Calil et al., 2016; Ferreira et al., 2016; Sampaio et al., 2018).

A vivência do trabalho coletivo e interdisciplinar foi considerada uma atividade expressiva, pois aprender a atuar e produzir em equipe aprimora várias habilidades e atitudes consideradas importantes para a prática em saúde, como a cooperação e o compartilhamento de saberes. A inter-relação com as equipes existentes na comunidade é apontada como uma prática positiva para a promoção da saúde (Moimaz et al., 2015; Oliveira; Almeida Júnior, 2015; Cortez; Silva, 2017; Carvalho et al., 2017; Sampaio et al., 2018).

Outro aspecto considerado na avaliação da ação extensionista é a percepção da comunidade atendida. Nos projetos desenvolvidos houve compreensão da importância da ação enquanto atividade favorecedora do entendimento do processo saúde-doença e autocuidado. $\mathrm{O}$ indivíduo atendido na comunidade é um potencial disseminador das informações e conhecimentos adquiridos. Nesta perspectiva, a ação extensionista contribui na habilitação de multiplicadores de ações promotoras da saúde (Calil, et al., 2016; Ferreira et al., 2016; Barros; Franco, 2018; Sampaio et al., 2018; Souza; Carvalho, 2018). 
Destaca-se, como ponto focal nessa discussão, a concepção de educação em saúde como uma das articulações que visa a formação de práticas educativas aplicadas para ensinar a comunidade a promover a saúde. Desta forma, a estratégia extensão universitária ganha relevância pela sua responsabilidade social na geração de conhecimento na população, por meio da motivação à participação, pelo estímulo a autonomia e o empoderamento para melhorar sua qualidade de vida.

\section{Os Desafios Para Implementação das Ações de Extensão no Âmbito da Saúde}

Embora a atividade de extensão seja percebida como uma estratégia positiva em inúmeros aspectos, como a formação de competências profissionais e a transformação das práticas em busca do comportamento de saúde, os autores enumeram fatores que são desafios para a implementação das ações junto à sociedade, conforme demonstrado no Quadro 2.

Quadro 2 - Fatores Percebidos Como Desafios Para Implementação das Ações de Extensão Universitária (2019)

\begin{tabular}{|c|c|}
\hline Fatores que dificultam a implementação da Ação de Extensão & $\begin{array}{l}\text { Estudo (s) que re- } \\
\text { ferem a problemá- } \\
\text { tica }\end{array}$ \\
\hline $\begin{array}{l}\text { Pouca adesão voluntária do discente aos projetos existentes por falta de } \\
\text { conhecimento, motivação em participar ou ainda em detrimento às ati- } \\
\text { vidades com remuneração como monitorias e bolsas de pesquisa. }\end{array}$ & Artigos 3, 5, 10, 11 \\
\hline $\begin{array}{l}\text { Reduzido reconhecimento da ação de extensão dentro da própria insti- } \\
\text { tuição, com maior incentivo e divulgação para as atividades de ensino } \\
\text { e pesquisa. }\end{array}$ & Artigos 3, 10 e 18 \\
\hline Escassas atividades de extensão direcionadas a promoção da saúde. & Artigos 2, 5 e 10 \\
\hline $\begin{array}{l}\text { Reduzido engajamento por parte dos próprios educadores, por inexis- } \\
\text { tência de projetos em sua área de atuação, desconhecimento das meto- } \\
\text { dologias e ainda, resistência a dedicação de horas extraclasse para pla- } \\
\text { nejamento e implementação das atividades. }\end{array}$ & Artigos 4 e 5 \\
\hline $\begin{array}{l}\text { Escassa estratégia de divulgação dos projetos na instituição e na comu- } \\
\text { nidade, reduzindo a amplitude de atendimento e o impacto das ações. }\end{array}$ & Artigo 10 \\
\hline Morosidade na elaboração e aprovação de novos projetos de extensão. & Artigo 5 \\
\hline
\end{tabular}

Fonte: Elaboração dos autores.

Observa-se que os fatores listados são relevantes e remetem às vulnerabilidades e aos desafios vinculados à execução de ações de extensão. Dentre elas, faz-se necessário destacar a pouca valorização da atividade extensionista no cenário da academia e as condições desfavo- 
Extensão Universitária como Prática Educativa na Promoção da Saúde

ráveis para sua prática. É imprescindível o estímulo a projetos fundamentados no diagnóstico situacional das reais necessidades da comunidade a ser contemplada, o incentivo à capacitação e ao engajamento dos docentes, a disponibilização de recursos para o desenvolvimento das intervenções e a ampliação de oportunidades de promoção à saúde (Moimaz et al., 2015; Oliveira; Almeida Júnior, 2015; Volpini et al., 2015; Calil et al., 2016; Oliveira et al., 2017; Deslandes; Arantes; 2017; Carvalho et al., 2017; Koglin; Koglin, 2019).

Enfatiza-se que durante a análise das publicações não foi observada contrariedade entre os autores nas categorias elencadas para discussão.

\section{Considerações Finais}

A análise dos artigos possibilitou considerar que a parceria entre a universidade e a comunidade pode ser compreendida como uma alternativa para promoção da saúde, por meio da vivência e da produção de conhecimento no contexto e cotidiano social. A atividade de extensão configura uma contrapartida, no âmbito da política de saúde vigente, junto à gestão das diversas esferas governamentais, objetivando contribuir na ampliação do atendimento à saúde com qualidade à população brasileira.

A ação de extensão universitária é uma ferramenta factível que tange a integralidade da assistência à saúde, nos diversos níveis de atenção, e ganha maior expressão na promoção da saúde por meio das práticas educativas e da reformulação de saberes na junção do conhecimento técnico-científico e popular.

Considerou-se que a vivência da extensão universitária propicia a interação sociocultural à comunidade acadêmica, fator que parece contribuir para o aprendizado e favorecer a percepção do processo saúdedoença.

Verificou-se que o convívio entre a comunidade e a academia fortalece a tríade ensino-prática-pesquisa, o que pode impulsionar o desenvolvimento de estudos em outras áreas de formação acadêmica, como as Ciências Humanas e Exatas. Considerando a ação de extensão universitária, como estratégia de formação e promoção de saúde, percebeu-se a necessidade de maior incentivo político e econômico, para seu fortalecimento e efetivação de sua proposta na academia e na comunidade.

Em nossa prática docente, nota-se que a inter-relação extensão universitária-formação profissional parece contribuir positivamente no desenvolvimento de competências para a atuação nos cenários de prática e no âmbito da promoção à saúde. O processo de ensino-aprendizado na comunidade pode configurar uma ação potencializadora de mudanças na prática educativa em saúde.

Entretanto, este estudo sinaliza que, para fortalecer a Extensão Universitária como estratégia educativa para discentes e comunidade, é necessário aprofundar as discussões na academia, fomentar projetos 
direcionados às necessidades da população a ser atendida e valorizar os docentes envolvidos.

Um dos fatores limitantes do estudo foi o reduzido número de publicações sobre as atividades de extensão universitária com uma reflexão sobre o seu impacto na formação dos profissionais ou voltadas à promoção da saúde, sugerindo a necessidade de maior valorização deste tema.

Por considerar a relevância e abrangência desta temática, bem como, perceber a necessidade de ampliar esta discussão e igualmente colaborar para a fomentação de novas publicações, sugere-se a inclusão no banco de Descritores em Ciências da Saúde (DeCS) do termo Extensão Universitária.

Recebido em 2 de dezembro de 2019 Aprovado em 25 de janeiro de 2021

\section{Nota}

1 Agradecemos à Fundação de Amparo à Pesquisa do Estado de Goiás (FAPEG).

\section{Referências}

ALVES, Roseane Aparecida dos Reis et al. Extensão universitária e educação em doenças sexualmente transmissíveis e temas relacionados. Revista da Universidade Vale do Rio Verde, Três Corações, v. 14, n. 2, p. 1079-1083, 2016.

BARROS, Fabiane Frigotto de; FRANCO, Adriana Cristina. Extensão Universitária em Saúde Ginecológica de Mulheres Trabalhadoras: educação para promoção da saúde. Revista Espaço para a Saúde, v. 19, n. 2, p. 43-53, 2018.

CALIL, Luciane Noal et al. Cuidado à Saúde da Mulher na Extensão Universitária: abordagem de uma experiência. Revista Baiana de Saúde Pública, Salvador, v. 40, n. 3, p. 796-807, 2016. DOI: 10.22278/2318-2660.2016.v40.n3.a2246.

CARVALHO, Vanessa Lôbo et al. Competências para Promoção da Saúde em Formandos dos Cursos da Área da Saúde. Revista de Enfermagem UFPE online, Recife, v. 11, n. 8, p. 3269-78, ago. 2017.

CORTEZ, Elaine Antunes; SILVA, Lauanna Malafaia da. Pesquisa-Ação: promovendo educação em saúde com adolescentes sobre infecção sexualmente transmissível. Revista de Enfermagem UFPE online, Recife, v. 11, n. 9, p. 3642-9, set. 2017.

COSTA, Deiziane Viana da Silva et al. Extensão Universitária na Promoção da Saúde Infantil: analisando estratégias educativas. Revista Ciência em Extensão, v. 11, n. 1, p. 25-31, 2015.

DESLANDES, Maria Sônia; ARANTES, Álisson Rabelo. Extensão Universitária como Meio de Transformação Social e Profissional. Sinapse Múltipla, v. 6, n. 2, p.179-183, 2017.

DEUS, Gabriela Brum de; KRUG, Marilia de Rosso. Avaliação de um Projeto de Extensão Universitária na Percepção de Professores da Educação Básica. Revista Conexão UEPG, Ponta Grossa, v. 14, n. 3, p. 446-453, 2018. 
Extensão Universitária como Prática Educativa na Promoção da Saúde

FERREIRA, Raquel et al. Promoção de Saúde Bucal e Síndrome de Down: inclusão e qualidade de vida por meio da extensão universitária. Odonto, v. 24, n. 48, p. 45-53, 2016.

KOGLIN, Terena Souza da Silva; KOGLIN, João Carlos de Oliveira. A Importância da Extensão nas Universidades Brasileiras e a Transição do Reconhecimento ao Descaso. Revista Brasileira de Extensão Universitária, v. 10, n. 2, p. 71-78, maio/ ago. 2019.

LIMA, Graziele Zamineli et al. Percepção de Acadêmicos de Enfermagem sobre o Cuidado em Saúde Mental em Domicílio: uma abordagem qualitativa. Revista de Pesquisa: Cuidado é Fundamental Online - RPCFO, v. 8, n. 2, p. 4255-4268, abr./jun. 2016.

MINETTO, Cleomar et al. A Extensão Universitária na Formação de Estudantes do Curso de Administração - UFFS. Revista Conbrad, Campus Cerro Largo, v. 1, n. 1, p. 33-46, 2016.

MOIMAZ, Suzely Adas Saliba et al. Extensão Universitária na Ótica de Acadêmicos: o agente fomentador das Diretrizes Curriculares Nacionais. Revista da ABENO, v. 15, n. 4, p. 45-54, 2015.

MORAES, Sandra Lúcia Dantas et al. Impacto de uma Experiência Extensionista na Formação Universitária. Revista de Cirurgia e Traumatologia Buco-MaxiloFacial, Camaragibe, v. 16, n. 1, p. 39-44, jan./mar. 2016.

OLIVEIRA, Camila da Silva; BRÊTAS, Ana Cristina Passarella; ROSA, Anderson da Silva. A Importância da Extensão Universitária na Graduação e Prática Profissional de Enfermeiros. Currículo sem Fronteiras, v. 17, n. 1, p. 171-186, jan./ abr. 2017.

OLIVEIRA, Franklin Learcton Bezerra de; ALMEIDA JÚNIOR, José Jailson de. Motivações de Acadêmicos de Enfermagem Atuantes em Projetos de Extensão Universitária: a experiência da faculdade Ciências da Saúde do TRAIRÍ/UFRN. Revista Espaço para a Saúde, Londrina, v. 16, n. 1, p. 36-44, 2015.

RIOS, David Ramos da Silva; CAPUTO, Maria Constantina. Para Além da Formação Tradicional em Saúde: experiência de educação popular em saúde na formação médica. Revista Brasileira de Educação Médica, v. 43, n. 3, p. 184-195, 2019.

SAMPAIO, Josineide Francisco et al. A Extensão Universitária e a Promoção da Saúde no Brasil: revisão sistemática. Revista Portal: saúde e sociedade, v. 3, n. 3, p. 921-930, 2018.

SILVA, Clarissa Bohrer et al. Atividades de Educação em Saúde Junto ao Ensino Infantil: relato de experiência. Revista de Enfermagem UFPE online, v. 11, n. 12, p. 5455, 2017.

SÍVERES, Luiz (Org.). Extensão Universitária como um Princípio de Aprendizagem. Brasília: Liber Livro, 2013.

SOUZA, Thais Cristina Flexa; CARVALHO, Jacira Nunes. A Percepção de Pais sobre Projeto de Extensão Universitária em Escola Amazônica. Enfermagem em Foco, v. 9, n. 3, p. 25-29, 2018.

VIEIRA, Francilene de Sousa et al. Inter-Relação das Ações de Educação em Saúde no Contexto da Estratégia Saúde da Família: percepções do enfermeiro. Revista de Pesquisa: Cuidado é Fundamental Online - RPCFO, v. 9, n. 4, p. 11391144, out. /nov. 2017.

VOLPINI, Carolina Rossato; NATALI, Paula Marçal; MÜLLER, Verônica Regina. Educação Social e Infância: atuação e formação profissional no projeto 'brincadeiras com meninos e meninas de/e na rua'. Motrivivência, v. 27, n. 46, p. 203213, 2015. 
Regis Rodrigues Santana é enfermeiro, graduado pela Universidade Federal de Goiás (UFG). Pós-graduado em Análise de Situação de Saúde, Saúde Pública e Estratégia Saúde da Família e Terapia Intensiva. Mestre em Ciências da Saúde pela Faculdade de Medicina (UFG). Docente em Graduação e Pós- Graduação em Saúde, com ênfase em Extensão Universitária. Coordenador do Projeto Educação em Saúde na Infância pela Universidade Salgado de Oliveira - Campus Goiânia-Goiás.

ORCID: http://orcid.org/0000-0002-0988-1997

E-mail: regisrsantana@gmail.com

Cristina Célia de Almeida Pereira Santana é enfermeira, mestre em Ensino na Saúde e doutoranda em Ciências da Saúde pela Faculdade de Medicina da Universidade Federal de Goiás.

ORCID: http://orcid.org/0000-0002-2030-2191

E-mail: ccaps44@gmail.com

Sebastião Benício da Costa Neto é psicólogo, pós doutor em Ciências Humanas pela Universidade Federal do Rio Grande do Sul. Professor Adjunto II na Pontifica Universidade Católica de Goiás.

ORCID: http://orcid.org/0000-0001-8160-3476

E-mail: sebastiaobenicio@gmail.com

Ênio Chaves de Oliveira é doutor, professor e orientador no Programa de Pós-Graduação em Ciências da Saúde da Faculdade de Medicina da Universidade Federal de Goiás.

ORCID: http://orcid.org/0000-0002-3502-7532

E-mail: ecol.br@gmail.com

Editora-responsável: Beatriz Vargas Dorneles

Este é um artigo de acesso aberto distribuído sob os termos de uma Licença Creative Commons Atribuição 4.0 Internacional. Disponível em: <http:// creativecommons.org/licenses/by/4.0>. 